Artículo Original

\section{Influencia del uso de Papacarie en el sellado marginal de obturaciones directas}

The influence of Papacarie use on direct restorations marginal seal

\section{Resumen}

El propósito de la investigación fue, comparar el sellado marginal de obturaciones directas, realizadas con la técnica sándwich, después de la remoción de tejido cariado con el gel de papaina (Papacarie) y el método convencional rotatorio. Para lo cual se seleccionaron 20 premolares humanos recientemente extraídos, con lesiones cariosas que comprometían la superficie oclusal y proximal. La muestra fue dividida aleatoriamente en dos grupos: Grupo 1: se hizo la remoción de dentina cariada, mediante la técnica químico mecánica utilizando el gel Papacarie. Grupo 2: remoción de dentina cariada mediante la técnica convencional, con instrumentos rotatorios. Después de la remoción del tejido cariado por ambas técnicas se colocó una restauración directa utilizando la técnica sándwich: colocación de ionómero de vidrio modificado por resina, sistema adhesivo de un solo paso y resina compuesta microhibrida. Posteriormente, después de un proceso de termociclado, los especimenes fueron sometidos a filtración pasiva del colorante azul de metileno, por 3 días, seccionados en sentido mesiodistal a través de la restauración, y observados de acuerdo a grados de filtración del colorante en la interfase diente-obturación tanto en el margen oclusal como el gingival de la preparación, con la ayuda del microscopio estereoscopio.

El análisis de los resultados indicaron que: El gel Papacarie permitió la remoción químico mecánica de tejido carioso en la preparación de cavidades para obturación. Sin embargo, influyó significativamente en una mayor frecuencia de filtración de colorante comprometiendo el sellado marginal de las obturaciones, comparado con el método de remoción convencional rotatorio.

\section{Abstract}

The purpose of the investigation was, to compare the marginal seal of direct restorations, carried out with the sandwich technique, after the removal of decayed tissue by means of papaine gel (Papacarie) and the conventional rotational method. So, 20 recently extracted human premolars were selected, with decay lesions that committed the oclusal and proximal surface. The sample was randomly divided in two groups: Group 1: the removal of decayed dentine was made, by means of the chemo mechanical technique using the gel Papacarie. Group 2: the removal of decayed dentine was made by means of the conventional technique, using rotational instruments. After the removal of decayed tissues by both techniques a direct restoration was placed using the sandwich technique, placement of glass ionomer modified by resin, adhesive system of a single step and micro hybrid composite resin. Then, after term cycling process, the specimens were subjected to passive filtration of blue methylene dye, for 3 days, cut through the mesiodistal way, and observed by stereoscopic microscope, according to degrees of blue methylene dye filtration at toothrestoration interface, in oclusal and gingival margins of the preparation.

The analysis of results indicated that: gel Papacarie permited the effective removal of decayed tissues for preparing restoration's cavities, however, it significantly influenced in a higher frequency of dye filtration, committing marginal sealing of restorations, compared with the rotational method of conventional removal.

\section{Martha Pineda Mejia ${ }^{1}$ \\ Doris Salcedo Moncada ${ }^{2}$ \\ Elmo Palacios Alva ${ }^{3}$ \\ Sonia Zambrano de la Peña ${ }^{4}$ \\ Waldo Gloria Zeballos ${ }^{5}$ \\ Julio Ochoa Tataje ${ }^{6}$ \\ Eduardo Ortiz Cardenas ${ }^{7}$}

litadora

3,4 Dpto. Académico Médico Quirúrgico

1-7 Facultad Odontología. UNMSM. Lima, Perú

Correspondencia:

Martha Pineda Mejía

Magíster en Estomatología

Dirección: Av. Germán Amézaga s/n, Lima 1, Perú Teléfono: 619-7000 / 3403

E-mail:mpinedam@hotmail.com

Palabras clave: Filtración marginal. Papaina. Restauraciones directas.

Keywords: Marginal leakage. Papaina. Direct restorations.

\section{INTRODUCCIÓN}

EEn las últimas décadas se han reportado en muchos países reducciones significativas en la prevalencia de caries. Estos resultados reflejan la efectividad de una odontología más preventiva que curativa; sin embargo, la enfermedad caries aun continua siendo una realidad prevalente, especialmente en los países en desarrollo. El perfeccionamiento de técnicas curativas y especialmente de materiales adhesivos permite hoy en día que el tratamiento restaurador sea cada vez más conservador. Siguiendo esta tendencia de mayor pre- servación de los tejidos dentarios, aparece como una opción adicional la remoción química de la dentina cariada ${ }^{13}$.

Ésta técnica de remoción de tejido cariado la inició en 1975 Habib y col. ${ }^{7}$, basándose en un efecto proteolítico no especifico del hipoclorito de sodio $(\mathrm{Na} \mathrm{OCl})$. El primer producto que apareció en el mercado con el nombre de CaridexTM, utilizaba un sistema que incluía ácido N-monocloro-DL-2-amino butírico (NMAB); sin embargo, éste sistema presentó una serie de problemas que afectaban la eficacia del propio método. La ineficacia en la remo- ción del tejido cariado, la necesidad de un gran volumen de la solución, el corto tiempo de efectividad de la solución empleada, alto costo, equipo voluminoso y pesado, instrumentos de difícil manipulación, así como metodología complicada, fueron las razones principales para dejar de producir y pensar en una nueva opción mas accesible ${ }^{13}$.

Siguiendo la misma línea de investigación, con el nombre de Carisolv ${ }^{\mathrm{TM}}$ (Medi Team Dentalutvekling Goteborg AB, Suecia), fue introducido en el mercado un nuevo sistema de remoción químico-mecánica 
para el tratamiento de lesiones de caries. Este método presenta un mecanismo de acción aparentemente similar al de Cari$\operatorname{dex}^{\mathrm{TM}}$, pero incorpora tres aminoácidos (ácido glutámico, leusina y lisina) los cuales substituyeron al ácido NMAB. Actúa propiciando un quiebre o ruptura de las uniones de las fibrillas colágenas del tejido afectado, dejándolo reblandecido para su fácil eliminación con instrumentos manuales. Sin embargo, el costo elevado del producto, especialmente para los países en desarrollo; la inestabilidad del preparado en un tiempo muy corto, están logrando la discontinuidad de uso del material ${ }^{13,17}$.

La más reciente introducción del gel a base papaina, desarrollado en Brasil, como método de resección dentinaria químico-mecánica, que se basa en la acción de la papaina, una enzima proteolitica extraida del latex de las hojas y frutos de la papaya, ha cobrado importancia, en parte por la eficiencia en la remoción de tejido dentinario cariado, costo relativamente bajo, estabilidad del preparado por tiempo prolongado. El gel de papaina ha sido preparado en el ańo 2003, por las investigadoras brasileñas: Dra. Sandra Kalil Bussadori, Odontopediatra profesora de la Universidad de Sao Paulo y Metropolitana de Santos y la Dra. Marcia Miziara, de la casa farmacéutica Formula \& Acción, se expende con el nombre comercial de PAPACARIE?

Las singulares ventajas de este nuevo sistema de remoción químico-mecánica de dentina cariada, permiten vislumbrar su creciente difusión futura ${ }^{17}$.

La papaina es una endoproteína semejante a la pepsina humana, la cual posee actividad bactericida, bacteriostática y antiinflamatoria, proveniente del latex de las hojas y frutos de la papaya verde madura, Carica papaya, cultivada en los países tropicales como: Brasil, India, Ceilan, África del Sur y Hawai. En relación a las otras enzimas naturales, la papaina posee algunas ventajas como: calidad y actividad enzimática; estabilidad en condiciones desfavorables de temperatura, humedad y presión atmosférica; encontrándose en alta concentración en el latex extraído de la cáscara de la papaya y conteniendo un elevado valor comercial debido a la diversidad de usos que presenta ${ }^{8}$.

El gel de Papacarie está compuesto por:

Papaina, Cloramina, Azul de toluidina (colorante), Sales, Conservantes, Espesantes y Vehículo csp.

Papaina: extraída del látex de las hojas y frutos de la papaya verde adulta, es una enzima proteolítica que posee propiedades bactericidas, bacteriostáticas y antiinflamatorias 14; actúa exclusivamente sobre el tejido dentario necrosado, ya que éste no posee la antiproteasa plasmática $\alpha_{1}$-anti-tripsina, que impediría la acción proteolítica de la papaina, por esta razón se produce un ablandamiento del tejido necrosado lográndose debridar las fibras de colágeno parcialmente degradadas, preservando el tejido sano por no estar desmineralizado ni tener fibras de colágeno expuestas ${ }^{8}$.

Cloramina: es un compuesto de cloro y amonio que tiene propiedades bactericidas y desinfectantes, utilizado para irrigación de conductos radiculares. Es un ablandador químico adicional de la dentina cariada, de modo que la estructura secundaria y/o cuaternaria del colágeno se ve afectada, rompiéndose los puentes de hidrogeno, lo que facilita la remoción del tejido cariado ${ }^{14}$.

Azul de Toluidina: es un colorante, que además actúa como un potente agente antimicrobiano, fijándose a la pared de la bacteria; es un fotosensibilizador no toxico utilizado porque la mayoría de bacterias bucales no absorben la luz visible. Potencializa la acción antimicrobiana del gel cuando se asocia la técnica al uso del laser de baja potencia ${ }^{14}$.

Silva et. al. ${ }^{8}$ evaluaron la citotoxicidad in Vitro del Papacaries realizando evaluaciones a corto plazo y largo plazo en cultivos de fibroblastos en diferentes concentraciones $(2 \%, 4 \%, 6 \%, 8 \%, 10 \%)$ de papaina y concluyeron que no existían diferencias, no demostró ser citotóxico in Vitro.

Bussadori y Silva ${ }^{9,6}$ mostraron las indicaciones del gel de Papacaries, el cual puede ser utilizado con éxito en pacientes con necesidades especiales, odontopediatría, adultos fóbicos, caries muy próximas a pulpa, es decir en cualquier lesión de caries, siendo una de las razones principales de su utilización en los ámbitos de salud publica debido a su bajo costo y no hay riesgo de contactar con los tejidos bucales por que no es toxico.

Se ha comprobado que el Papacaries adicionalmente es práctico, fácil de utilizar, bajo costo y no requiere del uso de anestesia local, comparado con el método tradicional usando instrumentos rotatorios, es menos doloroso, reduce riesgo de exposición pulpar, daño a los tejidos sanos, tornándose en una opción a traumática debido a la preservación de los tejidos sanos durante el procedimiento de remoción de caries ${ }^{4,10}$.

Pereira ${ }^{11}$ comparó el potencial antimicrobiano de Carisolv y Papacaries en relación al Estreptococo mutans y el Lactobacilo, informando que éste último mostró me- jor actividad antimicrobiana que Carisolv, por lo tanto es un material con un potencial antimicrobiano.

Maragakis GM y cols. ${ }^{12}$, evaluaron la cito toxicidad in vitro del Papacarie en cultivo de fibroblastos cuyo objetivo era verificar la biocompatibilidad de las diferentes concentraciones de papaina $(2 \%, 4 \%, 6 \%, 8 \%$ y $10 \%)$ para la estandarización del nuevo gel, y concluyeron que para el desarrollo del mismo, cualquiera de las concentraciones de papaina era factible.

En el normal desenvolvimiento de la odontología operatoria, la colocación de una restauración directa, es el procedimiento que complementa la preparación de una cavidad cariosa, haya sido realizada ésta, en la forma convencional, mediante el empleo de instrumentos rotatorios, o mediante la preparación químico-mecánica. El uso de elementos químicos en la preparación de la cavidad, podría influir en el grado de retención de las obturaciones definitivas, en el grado de filtración de líquidos en la interfase diente-restauración, alterando el sellado marginal de las restauraciones $^{15,16}$.

El método rotatorio o convencional de remoción del tejido cariado de los dientes puede presentar en muchos casos como inconveniente, la posibilidad de sobre extensión de la cavidad y exposición de la pulpa, siendo difícil evaluar exactamente cuanto de dentina puede ser removida1, además de la alta frecuencia de asociación del uso de instrumentos rotatorios con la producción de dolor ${ }^{2}$, así como el temor que llega a producirles a muchos pacientes, convirtiéndose en muchos casos en una barrera para la ejecución de un buen tratamiento ${ }^{3}$.

El propósito de ésta investigación es averiguar: cuál es la efectividad del sellado marginal producido en obturaciones directas con la técnica sándwich, cuyas cavidades se han preparado mediante el método convencional rotatorio o el método a base del gel de papaina.

\section{MATERIAL Y MÉTODOS}

Se seleccionaron 20 premolares humanos cariados recientemente extraídos, con cavidades que comprometían la cara oclusal y proximal, de mediana profundidad, se mantuvieron en una solución de suero fisiológica a una concentración de $10 \%$ de cloruro de sodio, en seguida se desinfectaron con una solución de glutaraldehido al $0,2 \%$ por 12 horas, y posterior lavado y limpieza de los residuos de tejidos por raspaje y profilaxis utilizando piedra pómez y agua, 
los dientes fueron nuevamente lavados en agua corriente y mantenidos en una nueva solución de suero fisiológico hasta el momento del experimento. Los dientes se distribuyeron aleatoriamente en dos grupos:

Grupo 1: $(\mathrm{n}=10)$ la remoción de tejido cariado se hizo con la técnica químico mecánica. Se procedió a la colocación del gel de papaina PAPACARIE ${ }^{\circledR}$ (Formula \& Ação Laboratorio Farmacêutico Ltda. SP. Brasil) en la cavidad de acuerdo a las instrucciones del fabricante, luego con la cureta para dentina, haciendo movimientos con la parte no activa se procedió a la remoción del tejido cariado, hasta encontrar una dentina transparente y dura.

Grupo 2: $(n=10)$ la remoción de tejido cariado se hizo con la técnica convencional con instrumentos rotatorios, utilizando una fresa redonda mediana, siempre manteniendo una refrigeración abundante.

\section{Procedimiento de obturación:}

La efectividad del sellado marginal de las obturaciones, se evaluó a través de la filtración marginal de colorante, para lo cual los dientes fueron sometidos a inmersión pasiva por 3 días a $37^{\circ} \mathrm{C}$ en el colorante azul de metileno al $20 \%$. Después fueron lavados, dejados secar y seccionados longitudinalmente a través de las restauraciones en sentido mesiodistal, para realizar la evaluación de filtración del colorante en la interfase diente restauración, en los márgenes oclusales y gingivales, mediante la observación en microscopio Estereoscopio a 40X. La evaluación de la filtración marginal se llevó a cabo por un solo examinador previamente calibrado, utilizando los criterios de valoración que se indican:

\section{Criterios de calificación de la filtra- ción de colorante}

Grado 0: No hay evidencia de penetración de tinta en la interfase diente restauración.

Grado 1: Penetración del colorante hasta la mitad de la profundidad de una pared cavitaria.

Grado 2: Penetración del colorante hasta la profundidad de una pared cavitaria.

Grado 3: Penetración del colorante hasta la profundidad de una pared incluyendo la base de la cavidad.

\section{RESULTADOS}

En la Tabla 1, se presentan los resultados en valores absolutos y porcentuales de la evaluación de la filtración del colorante en la muestra. En la evaluación del margen oclusal destaca un mayor porcentaje para el grado 0 (cero) en el grupo de remoción rotatoria del tejido cariado que para el grupo de remoción con el gel Papacarie (80\% y $45 \%)$ y lo contrario ocurre con el grado de filtración 1 que tuvo un porcentaje mas elevado para el gel Papacarie que para la técnica rotatoria $(45 \%$ y $15 \%)$, sin embargo el grado 2 solo se presentó en el grupo Papacarie y el grado 3 solo en el grupo rotatorio.

En el margen gingival (Tabla 2), el porcentaje de evaluaciones atribuidas al grado 0 (cero) fue mas elevado para el grupo de remoción rotatoria que para el grupo de remoción con gel Papacarie $(45 \%$ y $10 \%)$ y lo contrario ocurre con el grado de filtración 1 que tuvo un porcentaje mas elevado para el gel Papacarie que para la técnica rotatoria (60\% y 40\%), el grado 2 fue similar en ambas técnica $(5 \%)$ y el grado 3 mayor para el gel Papacarie que para la técnica rotatoria $(25 \%$ y $10 \%)$.

Comparando los resultados con respecto al margen oclusal, se encontró que la proporción entre no filtración y filtración del colorante fue de $(16 / 20)=0.8$ y $(9 / 20)=0.45$ para la técnica rotatoria y técnica Papacarie respectivamente, pero la diferencia entre ellas no mostró significancia estadística para la prueba McNemar $(p=0.092>0.05)$.

Sin embargo, en el margen gingival se encontró que la proporción fue de $(9 / 20)=0.45$ para la técnica rotatoria y $(2 / 20)=0.1$ para la técnica Papacarie, y la diferencia entre ellas si mostró significancia estadística para la prueba $\operatorname{McNemar}(\mathrm{p}=0.016<0.05)$.

Tabla N.o 1. Grados de filtración de las preparaciones cavitarias en el margen oclusal.

\begin{tabular}{lccccccccccc}
\hline \multirow{2}{*}{ Técnica } & \multicolumn{2}{c}{$\mathbf{0}$} & \multicolumn{2}{c}{$\mathbf{1}$} & \multicolumn{2}{c}{$\mathbf{2}$} & \multicolumn{3}{c}{$\mathbf{3}$} & \multicolumn{2}{c}{ TOTAL } \\
\cline { 2 - 11 } & $\mathbf{n}$ & $\mathbf{0}$ & $\mathbf{n}$ & $\mathbf{\%}$ & $\mathbf{n}$ & $\mathbf{\%}$ & $\mathbf{N}$ & $\mathbf{\%}$ & $\mathbf{n}$ & $\mathbf{\%}$ \\
\hline Papacarie & 09 & 45.0 & 09 & 45.0 & 02 & 10,0 & 00 & 0,0 & 20 & 100,0 \\
Rotatorio & 16 & 80,0 & 03 & 15,0 & 00 & 0,0 & 01 & 5,0 & 20 & 100,0 \\
TOTAL & 25 & 62,5 & 12 & 30,0 & 02 & 5,0 & 01 & 2,5 & 40 & 100,0 \\
\hline
\end{tabular}

Tabla N.o 2. Grados de filtración de las preparaciones cavitarias en el margen gingival.

\begin{tabular}{lcccccccccc}
\hline \multirow{2}{*}{ Técnica } & \multicolumn{2}{c}{$\mathbf{0}$} & \multicolumn{2}{c}{$\mathbf{1}$} & \multicolumn{2}{c}{$\mathbf{2}$} & \multicolumn{3}{c}{ 3 } & \multicolumn{2}{c}{ TOTAL } \\
\cline { 2 - 11 } & $\mathbf{n}$ & $\mathbf{\%}$ & $\mathbf{n}$ & $\mathbf{\%}$ & $\mathbf{n}$ & $\mathbf{\%}$ & $\mathbf{n}$ & $\mathbf{\%}$ & $\mathbf{n}$ & $\mathbf{\%}$ \\
\hline Papacarie & 02 & 10,0 & 12 & 60,0 & 01 & 5,0 & 05 & 25,0 & 20 & 100,0 \\
Rotatorio & 09 & 45,0 & 08 & 40,0 & 01 & 5,0 & 02 & 10,0 & 20 & 100,0 \\
TOTAL & 11 & 27,5 & 20 & 50,0 & 02 & 5,0 & 07 & 17,5 & 40 & 100,0 \\
\hline
\end{tabular}




\section{DISCUSIÓN}

La técnica químico-mecánica, esta desarrollándose cada vez más, por lo que el gel Papacaries podría resultar práctico, fácil de utilizar, de bajo costo y no requiere del uso de anestesia local, comparado con el método tradicional podría reducir el riesgo de exposición pulpar, daño a los tejidos sanos, tornándose en una opción atraumática debido a la preservación de los tejidos sanos durante el procedimiento de remoción de caries. Su bajo costo podría incluso convertirse en una de las razones para su utilización en el ámbito de la Salud Pública ${ }^{17}$.

De acuerdo con los resultados de las tablas presentadas la frecuencia de casos de filtración marginal fue superior en el margen gingival que en el oclusal en ambas técnicas. Sin embargo, los grados de filtración más severos (grado 3) fueron relativamente pocos en ambas técnicas, siendo el grado 1, o sea la filtración hasta la mitad de una pared, lo que se produjo con mayor frecuencia.

Ahora este resultado de mayor grado de filtración marginal en la pared gingival en relación a la pared oclusal, era de esperarse pues la obtención de sellado marginal en gingival constituye todavía una etapa crítica. Autores como Dibb et al. ${ }^{18}$, también identificaron ese problema incluso cuando evaluaron la filtración marginal en restauraciones clase $\mathrm{V}$ con bordes en esmalte y en dentina/ cemento utilizando varios materiales restauradores (resina compuesta modificada con poli ácidos y un cemento de ionómero de vidrio modificado por resina).

Las grandes fallas de las restauraciones estéticas continua centrada en los márgenes gingivales localizados en las proximidades de dentina o cemento, donde la adhesividad es más difícil de ser obtenida debido a la compleja estructura dentinaria y la continua exudación de fluidos provenientes de la pulpa (Farias, Avelar, Bezerra) ${ }^{3}$. Para los autores, el sellado de los márgenes cavitarios en gingival utilizando materiales fotoactivados, también se ve comprometido por la contracción de polimerización que sufren, lo cual compartimos para efectos de ésta investigación. La fuerza de unión de los sistemas adhesivos, cementos de ionómero de vidrio modificados por resina y resinas compuestas, es insuficiente durante la contracción de polimerización, lo que provoca un apartamiento de la restauración en la región gingival formándose gaps que permiten la penetración de fluidos y bacterias.

La permeabilidad marginal en la interfase diente-material restaurador ha sido objeto de estudio por una gran cantidad de investigadores quienes enfatizan que los márgenes de las restauraciones no son fijos, inertes o impenetrables, mas bien en ellos existen microgrietas dinámicas que contienen una gran cantidad de iones, moléculas y toxinas que pueden representar un fenómeno importante relacionado con las fallas presentadas en las restauraciones (Cox et al. $)^{19}$.

La microfiltración marginal puede ser casi eliminada en las regiones con espesor suficiente de esmalte, gracias al procedimiento de acondicionamiento ácido. Sin embargo, en áreas en las cuales las restauraciones poseen interfase con la dentina o el cemento, forman adaptaciones pobres con el subsiguiente pigmentado del margen, o el surgimiento de caries secundarias. La adhesión a dentina es más difícil pues ella es estructuralmente más compleja que el esmalte, presentando muchas variables que impiden su adhesión a los materiales ${ }^{17}$. De acuerdo con Farias, Avelar y Bezerra $^{3}$, la unión a esmalte es una práctica fácilmente obtenida y de éxito.

A través del análisis de los datos de la investigación, podemos concluir que la mayor filtración en la pared gingival del grupo que uso el gel Papacarie comparado con el grupo de preparación rotatoria, mostró una diferencia estadísticamente significante, lo que sugiere que la técnica de remoción de tejido cariado está realmente influyendo en el grado de filtración de alguna manera. $\mathrm{O}$ sea que el método de remoción químico-mecánica, con el gel Papacarie, aumentó el grado de filtración observado en el margen gingival de las muestras evaluadas.

Podríamos explicar que el uso del gel Papacarie para preservar la estructura dentaria, muchas veces puede dejar zonas de esmalte sin apoyo dentinario, lo cual podría justificar la diferencia observada entre los grupos en ésta pared, siendo, por lo tanto un dato a ser mas investigado en otros estudios.

Bajo las condiciones de éste estudio, se llegó a las siguientes conclusiones:

1. Las dos técnicas de remoción de tejido cariado, la convencional con instrumental rotatorio y la químico mecánica con aplicación del gel Papacarie, permitieron la filtración marginal de colorante en restaura- ciones directas de cavidades ocluso proximales.

2. Para ambas técnicas de remoción de tejido cariado no hubo diferencia en la filtración en el margen oclusal de las restauraciones.

3. La técnica de remoción de tejido cariado mediante la aplicación del gel Papacarie permitió significativamente mayor filtración en el margen gingival que la técnica convencional con instrumental rotatorio.

4. El margen gingival permitió mayor filtración marginal que el oclusal.

\section{REFERENCIAS BIBLIOGRÁFICAS}

1. Naressi SC, Araujo MA. Comparação marginal de restauraçoes adhesivas empreñando instrumento rotatorio ou sistema químico-mecanico na remoçáo de tecido cariado. RPG Rev Pos-grad São Paulo. 2001; 8(4): 313-321.

2. Anusavice KJ, Kincheloe JE. Comparison of pain associated with mechanical and chemomechanical removal of caries. J Den Res. 1987; 66(11): 1680-83.

3. Farias DG, Avelar RP, Bezerra AC. Estudo comparativo da infiltração marginal em restauraçóes de classe V. Pesqui Odntol Bras, São Paulo. 2002; 16(1): 83-88.

4. Silva LR, Tonolli G, Santos EM, Bussadori SK. Avaliação da biocompatibilidade "in vitro" de un novo material para a remoçáo química e mecânica da carie. Pesq Odontol Bras. 2003; 17 sup. 2.

5. Candido LC. Nova abordagem no tratamento de feridas. Sáo Paulo: SENAC-SP; 2001.

6. Bussadori SK y cols. Avaliação da biocompatibilidade "in vitro" de un novo material para a remoçáo química e mecânica da carie - Papacarie. Pesq Bras Odontoped Clin Integr. 2005; 5(3): 253-59.

7. Habib CM, Kronman JH, Goldman M. A chemical evaluation of collagen and hydroxyproline after treatment with GK-101. Pharmacol Ther Dent. New Cork. 1975; 2: 209-215.

8. Silva LR, Motta LJ, Reda SH, Facanha RA, Bussadori SK. Papacarie. Un novo sistema para remocao quimica e mecánica do tecido cariado. Relato do caso clínico. Revista da SOEPS 2004; 26(6): 4-8. 
9. Bussadori SK, Silva LR. Papacarie: um novo método para remoçáo química mecânica da carie dentaria. [S.I.] 2003. disponible en: <http://odonto.com.br/lerartigo. asp?cat=1\&area $=2 \& \operatorname{cod}=1>$

10. Silva RC, Raggio DP, Imparato JC. Avaliação da microinfiltração marginal de dois cimentos ionomericos de dentes deciduos utilizados no tratamento restaurador atraumatico. Rev Paul Odontol. 2004; 26(2): 27-29.

11. Pereira SA, Silva LR, Motta LJ, Bussadori SK. Remoção químico mecánica de carie por meio do gel Papacarie. RGO, Porto Alegre. 2004; 52(5): 385-388.

12. Maragakis GM, Hann P, Hellwing E. Clinical evaluation of chemomechanical caries removal in primary molars and its acceptance by patients. Caries Res. 2001; 35: 205210.
13. Villena, Rita. La resección químico mecánica de la dentina cariada: una opción emergente. En: Henostroza G. (ed.) Estética y operatoria dental. $1^{\text {a }}$. ed. Lima: Multi-impresos S.A.; 2002; pp. 33-34.

14. Flindt M. Health and safety aspects of working with enzymes. Process Biochem 1979; 13(8): 3-7.

15. Urzua I, Stanke F, Marine A. Nuevas estrategias en cariologia. Santiago de Chile: Facultad de Odontología Universidad de Chile; 1999.

16. Martine A, Stanke F, Urzua I. Caries: Tratamiento de una enfermedad infectocontagiosa. $1^{\text {a }}$ ed. Santiago de Chile: Facultad Odontología Universidad de Chile; 1997.

17. Araujo N, Oliveira A, Rodrigues V, Andrade P. Avaliaçao do selamento marginal de restauraçoes adesivas após o uso do gel de papaia. Pesq Bras Odontoped Clin Integr. 2007; 7 (1): 67-73.
18. Dibb RG, et. al. Avaliaçao in vitro da microfiltraçao marginal em restauraçoes classe $\mathrm{V}$ de materiais restauradores estéticos. Rev Odontol UNESP. 2001; 30(1): 75-86.

19. Cox CF; Keall HJ, Ostro E. Biocompatibility of surface-sealed dental materials against exponed pulps. J Prosthet Dent. 1987; 57(1): 18.

Recibido: 02-11-08

Aceptado para publicación: 12-12-08 